\title{
Study on the Prevention and Cure Security Strategy of China's Occupational Diseases
}

\author{
Feng PAN \\ China Center for Industry Security Research, \\ Beijing Jiaotong University \\ Beijing China \\ e-mail: 58285421@qq.com
}

\begin{abstract}
Environmental damages and physical damages to workers in the low-cost production searching process during capital globalization are challenges that all mankind are facing with. The whole international society have carried out extensive and deep researches on occupational diseases. Although different countries are at different economic development stages and different legislations and levels of law enforcement, the legislation goal of different countries is to protect survival right of bottom of the society. Due to effects of China's economic level and social power structure, the prevention and cure strategy of Chinese occupational disease hasn't been explored thoroughly. This problem was analyzed in this paper.
\end{abstract}

Keywords-occupational disease; psychoneurosis; prevention and cure safety

\section{INTRODUCTION}

Existing application system of occupational disease treatment in China neither considers that migrant workers have become main victims of pneumoconiosis nor neglects pathogenesis of pneumoconiosis. In reality, migrant workers are lack of basic knowledge on prevention and cure of occupational disease as well as basic dust keeper and protective equipments during the labor process. After most patients show preliminary symptoms of pneumoconiosis, they are fired by the employer through mandatory or fraudulent means. After clinical symptoms of pneumoconiosis occurs after the incubation period, laws and regulations based on existing labor relation have become the institutional guarantee of treatment application of occupational disease. They not only have to burden the diagnosis and treatment costs which are difficult to expect, but also couldn't gain subsequent treatment cost without existing labor relations with employers. They even may lose the qualification of application for identification of injure accidents due to restricts of local policies. These barriers hinder patients to acquire effective cure after progression of disease. Patients can only recur to labor dispute arbitration and judicial procedure and depend their rest lives on the tedious long procedure. This is extremely unfair to patients with pneumoconiosis who are struggling with death threats.

On the rights protection road of patients with pneumoconiosis, employers who have no restricts on morality, laws and workers' collective power are the main capital barriers. They escape from their responsibilities by all means according to legal permission and legal loopholes. Physical examination to dust exposed workers before assumption and demission is originally legal responsibility, but it is used by the employers as the mean of early diagnosis of pneumoconiosis. Termination of labor relations is a normal behavior of employees and employers in the market economy. However, it is used by employers as one mean to abandon workers with early pneumoconiosis. Even business operation forms like enterprise moving, name change, alteration of judicial person and consolidation of capitals can be ways for the employer to escape from liability of compensation. Employers take the full advantages of long incubation period of pneumoconiosis and patients' inadequate knowledge on pneumoconiosis to create various barriers against claim for compensation based on spatial and time differences. Employers who play the tyrant in a locality even can make full use of relationship with local officials will set at the law naught openly, view existing rules nothing, and refuse the compensation liability directly.

\section{InSTITUTIONAL PROBLEMS IN CHINA'S OCCUPATIONAL DisEASE PROTECTION}

The rapid growth of new pneumoconiosis in this century is the consequence of government's blind emphasis on economic development, but neglecting social justice and labor's rights. Such bad consequences still exist on the rights protection road of patients. Under bribes and power threats of employers, potentates of diagnosis and identification of occupational diseases, identification of injure accident, evaluation of labor capacity, accounting of occupational disease treatment, labor dispute arbitration and judicial adjudication make the original simple and just procedures as barriers which are difficult to be overcome during compensation claiming of patients. In these procedures, institutional rigidity and defects are amplified by operations of the potentates and diagnosis certificate of remote occupational disease prevention and cure hospitals is not approved by organizations in the place of enterprises. Unscrupulous means and utilitarianism nature of capital are marked by "legal" sign by potentates. Arbitration and judicial organs regard employers' behavior of terminating the labor relations with patients with early pneumoconiosis as a "just cause" of reject patients' requests. When the original four-step procedure evolves to complicated steps 
due to institutional, capital and power barriers and numerous patients with pneumoconiosis fall down on the endless road of rights protection, we have to notice a topic beyond this report ------ "play politics". Maybe, designers of the program for occupational disease diagnosis and identification of injure accident hope to endow this program with simplicity, justice and rigidity. However, when the potentates show favor or scruple towards to capitals deliberately, the rigidity of the procedure offer them a space to "play politics". They can change this simple procedure into complicated steps, create it a barrier against patients' compensation claiming for occupational diseases, and even can develop it a trading pit of "collusion between government and businessmen". When fraudulent practices of potentates forces a patients with IIIstage pneumoconiosis to prove the diagnosis through "chest operation", we are difficult to define behaviors of potentates as "administrative omission" or "malpractice". Their behaviors remind us that a cold-blooded people are making fun of helpless people continuously.

Many institutional obstacles interweave mutually and finally form a huge structural barrier against claim for compensation, thus increasing difficulty of claim for compensation of patients with pneumoconiosis significantly. Institutional barrier lays the foundation for the employer to construct capital barriers. In diagnosis and identification of occupational disease, they can refuse to offer necessary related documents, thus setting capital barriers at the beginning of compensation claiming procedure of pneumoconiosis. Power obstacle is an essential consequence of "collusion between government and businessmen". Diagnosis and identification of injure accident organizations of pneumoconiosis, authentication organization of occupational injury, certification organization of labor capacity, arbitral institution organization of labor disputes and related personnel of judicial organs all can dissimilate compensation claiming procedure for patients with pneumoconiosis by taking advantages of institutional rigidity and defects as well as their public powers.

Two key problems that China's prevention and cure strategy of occupational disease is facing with are behind these three types of obstacles, namely, "collusion between government and businessmen" and labor weakness. These two problems have been mentioned in the research report published by the China Labor Bulletin and are necessary to be reaffirmed in this paper. When government officials who use local GDP as the "stepping stone" to their official career find mercenary employers, the beneficial pursuit at the cost of environment and labor rights becomes the node of "collusion between government and businessmen". Once the government kills bud of labor organization and deprives their collective negotiation rights, labors are trampled upon at will. These two problems not only result in continuous high incidences of occupational disease and industrial accidents, but also extend to the rights protection field of patients with pneumoconiosis and form the background of three barriers. It goes without saying that capital obstacles formed by labor weakness is similar with power obstacles formed by "collusion between government and businessmen". In other words, institutional obstacles are also in this background. We can discover that it is these two problems that make lawmakers neglect universal labor rights and special care to patients with pneumoconiosis during the law making process.

\section{RESEARCH ON RightS PROTECTION MECHANISM OF PATIENTS WITH OCCUPATIONAL DISEASES}

\section{A. Construction Idea of Changing the Prevention and Cure Strategy of Occupational Diseases}

The prevention and cure strategy of occupational diseases in China has been following the principle of "prevention first". This requires enterprises to adopt effective protection measures of occupational diseases and provides protective devices to labors; set occupational health management organization and equip with professionals to be responsible for occupational disease control; make plans and implementation programs on occupational disease control; establish and perfect the occupational health management system and operation rules, occupational health files and labors' health monitoring files, risk factor monitoring and evaluation system for occupational disease in working places, as well as accident emergency rescue plans of occupational diseases. The design idea of this control system neglects reality of abundant private middle and small-sized enterprises (SMEs) and family workshops in China. They are a kind of production and management unit formed by drives of economic benefits. They are born from production sources, survive according to state of business, and eliminated by market competition. Quite a number of them neither have qualification of legal persons nor in the view of business administration departments and occupational disease control authorities, thus difficult to meet most institutional requirements, such as establishing occupational disease control system and files. This is an inevitable reality in the economic development process and a fact that couldn't be eliminated in a short period. Hence, the government shall adopt classified management mode rather than current impractical and uniform construction idea of occupational disease control system.

Establish employment fields for dust exposed workers. Enterprises with qualification of legal persons are still asked to establish all systems under supervision and guidance of related government departments according to regulations in the Law on Prevention and Control of Occupational Disease. Related government department shall assume the responsibility to supervise individual workshops, small mines and factories without qualification of legal person, and establish management-related systems and files for them except for providing necessary occupational disease control facilities and individual protective goods. Firstly, a strict employment registration system for workers in dusty environment shall be constructed. Employers are asked to submit general information of related personnel and report personnel changes regularly. Related government departments shall create and store employment files of dust exposed workers, which are used as basis of subsequent pneumoconiosis diagnosis and identification of injure accidents. 
Regular examination of pneumoconiosis. So far, the government is lack of accurate statistical data on pneumoconiosis which ranks the first in occupational diseases, which causes the chaos and exploring state of prevention and treatment of pneumoconiosis. The latest nationwide survey is the "National Dust (Silicon) Lung Epidemiological Investigation Research" organized by the Ministry of Health in 1987. China's enterprise structures have changed greatly in the past 20 years and most pneumoconiosis occurs in SMEs. In recent years, some experts have proposed that the called "million" of miners with pneumoconiosis is just an estimation based on experiences and couldn't be used as the basis for pneumoconiosis control design and policy making. The central government shall have regular examination plans of such occupational disease, especially for SMEs engaged in high-dust environment. Migrant workers exposed to dust in SMEs are key objects of the examination. Such examination shall be implemented every 3-5 years at the cost of government and employers. For enterprises with largescaled occurrence of pneumoconiosis in the general investigation, the government health supervision department shall adopt measures to supervise and urge employers to improve working conditions, equip with dust reduction facilities, apply wet-type operation or change raw materials that generate dusts.

Popularize knowledge on pneumoconiosis. One causes of the sharp growth of pneumoconiosis in China in recent years is that migrant workers know less about harms of pneumoconiosis caused by dust exposed jobs and lack of self-protection consciousness. This is related with All China Federation of Trade Unions (ACFTU) neglecting their right protection. At end of the last century, although the government relaxed restricts on migrant workers, she neglects essential popularization of knowledge on occupational disease prevention and labor rights protection. Many workers don't understand damages of high-dust exposed jobs, pathogenesis and early symptoms of pneumoconiosis, deserved rights and acquisition ways after attacked by occupational diseases. These problems haven't attract high attentions from labor unions of ACFTU. Government and labor unions at all levels shall popularize knowledge on pneumoconiosis prevention and control and use policies and laws of occupational disease treatment as the key of right protection of migrant workers. They shall make full use of various media and corresponding means, or powers of non-governmental organizations like labor unions and migrant workers to promote laws and knowledge related to pneumoconiosis prevention and control as well as occupational disease treatment. The government and labor unions who use funds collected at the name of "assisting migrant workers" to this program will achieve benefits beyond measure. This possesses more substantive significance and actual effects than whitewash projects, such as "Occupational Recruitment Project", "Legal Aid Project" and "Technical Training Project".

Establish the worker participation system. China Labour Bulletin always advocates that establishing the occupational safety and health supervision management system in enterprises with worker participation is a long-term effective mechanism of inhibiting and reducing occupational diseases truly. In enterprises, it is workers that concern their life safety and physical health mostly. Occupational disease protection and safety accident prevention measures can be executed effectively as long as they play a role in occupational safety and health monitoring. Specifically, workers shall be able to organize the labor union that can represent their own interests really, and participate in management and supervision of occupational safety and health conditions of enterprises. Only the collective negotiation power of workers than can force employers to improve working conditions, increase occupational safety and health protection devices, and offer qualified protective goods to workers. Moreover, capital barriers and power barriers can be overcome only through such independent worker power.

\section{B. Simplify the Rights and Interest Remedy Procedure for Patients with Pneumoconiosisi}

We should say that China's procedure of occupational disease diagnosis and identification of injure accident is not complicated. However, it is very complicated and excessively rigid in reality, which are attributed to institutional mistakes and "playing politics" by the procedure operators. Therefore, it is necessary to restore the original simple steps of this procedure through administrative means and legislation mechanism, thus enabling patients with pneumoconiosis acquire prompt assistance in a short time through this procedure.

Establish the procedure for pneumoconiosis diagnosis and identification of injure accidents. During rapid economic development at end of the last century and early of this century in China, high-dust production enterprises like jewel crafting, construction and mining are generally facing with supply shortages of anti-dust devices and tools. With considerations to long incubation period of pneumoconiosis, most patients fired by employers and continuous high incidence of new pneumoconiosis in future, a set of diagnosis and identification procedure different from other occupational diseases shall be set up. In this procedure, method to overcome capital and power obstacles that patients with pneumoconiosis encountered during claim of compensation shall be designed and a "convenient door" for labor relation confirmation, necessary application documents, remote diagnosis certificate, prescription of identification of injure accidents shall be open to patients with pneumoconiosis according to specific difficulties and the principle of "legal, justice and timeliness".

Revise and execute laws for the convenience of right and interest remedy. Laws on occupational disease treatment shall be obey to the principle of favoring right and interest remedy, which is nothing better than procedure simplification. If competent government departments can establish employment files to dust exposed workers, it can help to trace incidence time and location of pneumoconiosis and define the labor relation between patients and employers, which can prevent missing of labor relation certificate in the following diagnosis and identification. In 
these procedures, patients shall be allowed to use existing legal convenience, such as accepting remote (living place) diagnosis of occupational disease prevention and cure organizations. In addition, the legislative institutions shall revise laws hindering right and interest protection of patients, for example, qualification of automatic promotion after progression of pneumoconiosis, allowing the court to accept civil compensation lawsuit request of patients, direct access to court for dispute between patients and employers or employment injury insurance organizations, allowing advance execution of the court based on disease state of patients with consideration to follow-up treatment cost in judgment under the basic affirmation of fact, etc.

Establish an assistance mechanism for patients with pneumoconiosis. Patients with pneumoconiosis walks on the right protection road with weak bodies, which is a large sneer against China's human rights. Without adequate folk rights organization for coordination between patients and employers. An assistance mechanism for patients with pneumoconiosis shall be established between governments of patients' living place and employers' location. These two governments shall be held responsible for coordinate the remote right protection issues. It is suggested that local governments in regions with high incidence of pneumoconiosis shall set up a right protection team composed of members from government health supervision, occupational safety supervision, human resources and social insurance and judicial departments. This team is responsible for coordination between occupational disease treatment affairs and related government department where employers locate in, thus enabling patients with pneumoconiosis gain prompt treatment and aids in time. To protect living standard of patients as well as their family members, local government shall include patients with pneumoconiosis who couldn't offer labor relation certificate into the object of local minimum living security and provide them essential medical treatment conditions at the cost of government.

Establish treatment and insurance funds to patients with pneumoconiosis. In China, there are abundant patients with pneumoconiosis who haven't received timely treatment due to failures in labor relation certificate or finding the original employers and are caught in hopeless situation because of the illness. The government shall take forcible measures, extract a certain proportion of treatment expenses for pneumoconiosis according to output values of high-dust enterprises, and set up the treatment and insurance funds to patients with pneumoconiosis. The funds are mainly used as emergency treatment cost and minimum standard of living for diagnosed patients before receiving compensations for occupational injury. It is suggested to holding related government department responsible for fund raising and operation, determining different fund rates according to enterprise scale and dust concentration in working places, open a special account at bank, and formulate related systems for fund payment standards and means.

\section{Establish the Social Supervisory System for Occupational Disease Identification}

This report reveals power barriers against pneumoconiosis diagnosis and identification of injure accidents, which highlights the serious dissimilation of public power. Since there's no public supervision system of occupational disease diagnosis and identification in the society, power supervision is only limited within selfsupervision mechanism in related government organizations. Such supervision is useless to inhibit dissimilation of power powers. As a result, external social supervision shall be an essential way to inhibit power dissimilation and eliminate the power barrier against claim of compensation for patients with pneumoconiosis.

Construct the social supervision system of pneumoconiosis diagnosis and identification of injure accidents. Firstly, the supervision qualification of folk team on operations of these systems shall be determined. Government shall select legally registered folk teams according to administrative divisions, give them power to supervise pneumoconiosis occurrence in high-dust enterprises, and offer material, capital and training supports. Secondly, supervision duties and corresponding powers of folk teams shall be defined, including: (1) supervise occupational health conditions of high-dust enterprise according to clues from workers and report existing problems to related government departments; (2) supervise pneumoconiosis diagnosis and identification of injure accidents, cope with reports of workers and patients, and question related functional departments; (3) propose administrative review to labor capacity authentication and identification organizations of injure accidents on the behalf of patients with pneumoconiosis; (4) bring administrative lawsuit against these organizations to the court on the behalf of patients with pneumoconiosis.

As a quasi-governmental organization, ACFTU shall take the initiative to pneumoconiosis prevention and assistance to patients if it still wants to appear as the "public organization". Local unions shall encourage and support migrant workers to organize unions in high-dust enterprises or assist workers to set up the occupational safety and health supervision committee in enterprises (or occupational safety and health supervision team), and set up the occupational safety-health combined supervision committee in local regions. Members of the committee shall be representatives selected by workers. Under mature conditions, encourage and guide enterprise labor unions to make collective negotiation with employers on occupational safety and health issues and sign special collective contact. Additionally, local unions shall provide legal aids to claiming of compensation for patients with pneumoconiosis and offer patients who are pursue right protection in places other than their own hometown accommodation conditions when necessary.

Pneumoconiosis has occupy the first role in occupational diseases in China and has a population of over one millions. If patients couldn't acquire proper treatments or reasonable economic compensation, it will cause numerous disputes on 
rights and interests. The large-scaled occurrence of pneumoconiosis in one enterprise or one region will cause mass disturbance of collective pursuit of rights and interests. Although government can solve collective disputes and typical cases by "handling special cases with special methods", right and interest protection of patients with pneumoconiosis can only be realized by eliminating three types of barriers against claim of compensation.

\section{REFERENCES}

[1] E-kaufman ,labor and Employment Regulation:Neoclassical and Institutional.

[2] Barbash ,Collective Bargaining:Contemporary American Experience Reading in Labor Economics and Labor Relations.Ed Lloyd.

[3] Barging Equanimity Industrial Relations,American labor law ,1992. 